\title{
História e memória do Programa de Pós- Graduação em Educação da Universidade Federal do Paraná (1975-2020)
}

\section{The History and memory of the Postgraduate Program in Education of the Federal University of Paraná (1975-2020)}

\author{
Marcus Levy Bencostta* \\ Marília Andrade Torales Campos* \\ Cláudio de Sá Machado Júnior*
}

\begin{abstract}
RESUMO
Este ensaio trata de um registro de memória que se soma às celebrações dos 45 anos de funcionamento do Programa de Pós-Graduação em Educação (PPGE) da Universidade Federal do Paraná (Brasil). Trata-se, portanto, de uma narrativa escrita a seis mãos, cujo objetivo é narrar e promover uma reflexão sobre os momentos importantes que marcaram profundamente a experiência histórica e a contribuição acadêmica que este Programa de PósGraduação acumulou ao longo de quatro décadas e meia na formação de mestres e doutores em Educação. Para compor a trama de dados sobre a história do PPGE, foi feita uma revisão de documentos como: os relatórios anuais (1975-2020), as atas de reunião do colegiado e os textos já publicados sobre a trajetória do Programa. A narrativa, feita por professores que atuam no PPGE, buscou descrever três períodos definidos a partir de uma cronologia marcada pelas fases de criação, consolidação e prospecção do Programa. A partir desta revisão histórica, foi possível destacar elementos que permitem compreender a história do PPGE nos contextos nacional e regional resguardando suas singularidades, bem como apontar linhas e tendências para sua futura evolução.

Palavras-chave: História da Educação. Educação Universitária. Pós-Graduação em Educação. Pesquisa.
\end{abstract}

* Universidade Federal do Paraná. Programa de Pós-Graduação em Educação. Curitiba, Paraná, Brasil. E-mail: marcus@ufpr.br - http://orcid.org/0000-0003-3387-7901 E-mail: marilia. torales@ufpr.br - http://orcid.org/0000-0002-4026-6239 E-mail: claudiojunior@ufpr.br - http:// orcid.org/0000-0001-6430-8782 


\begin{abstract}
This essay is a record of memory that is part of the celebrations of 45 years of the Postgraduate Program in Education (PPGE) of the Federal University of Paraná (Brasil). It is, therefore, a narrative written by three people, the objective of which is to narrate and promote reflection about important moments that profoundly marked the historical experience and academic contribution that this Postgraduate Program in Education has accumulated over four and a half decades in producing Masters and Doctors of Education. In order to compose the plot containing data on the history of the PPGE, we reviewed documents such as: its annual reports (1975-2020), the minutes of the meetings of its collegiate board and texts published about the trajectory of the Program. The narrative, written by PPGE teachers, has sought to describe three periods based on a timeline marked by the creation, consolidation and prospection stages of the Program. Based on that historical review, we have been able to pinpoint elements that enable the history of the PPGE to be understood within the national and regional contexts and their singularities, while also indicating courses and trends for its future evolution.
\end{abstract}

Keywords: History of Education. University Education. Postgraduate Programs in Education. Research.

\title{
Introdução
}

$\mathrm{O}$ ato de comemorar presente nos eventos individuais e coletivos reivindica à memória e à história o modo como eles são representados. Apesar de sua origem religiosa, o sentido de commemoratio que utilizaremos a seguir nos remete a refletir sobre a identidade daquilo que selecionamos e organizamos de modo consciente para celebrar. E se, por um lado, esse uso, certamente, contribui para pensarmos este ato estruturado em uma experiência que é própria daquela(e)s que dele participam, por outro, destacamos que a relação, nem sempre amistosa, entre memória e história, merece atenção nesse contexto de celebração dos momentos que escolhemos para lembrar, mas, também, reconhecemos o risco de esquecer outros e, em especial, aqueles momentos silenciosos e "não ditos". Nesse sentido, podemos reafirmar, como fez Mona Ozouf (1999, p. 31), que "comemorar é uma atividade estranha, que oscila entre presença e ausência".

E quando estamos aqui no tempo presente, tentando nos apropriar de uma experiência que se originou em 1975, quando teve início o funcionamento do Programa de Pós-Graduação em Educação (PPGE) da Universidade Federal do Paraná (UFPR), que se estende até o tempo mais próximo e imediato da 
Pandemia do COVID-19, em 2020, não queremos de modo algum reconstruir ou transportar para hoje os diferentes acontecimentos que marcaram os 45 anos do PPGE, mas provocar uma reflexão sobre os sentidos possíveis que podemos extrair nesse momento de comemoração.

O estudo das singularidades históricas do PPGE nos permitiu interrogar os traços de sua experiência como uma tentativa de interpretar aspectos dessa herança comum à toda(o)s que dela participam. A importância que representa 0 patrimônio herdado não nos permite cometer descontextualizações que isolem tais singularidades a ponto de comprometer a perda de compreensão de seu sentido ao formular narrativas mitificadas ou idealizadas. Sobretudo, por se tratar de uma rememoração que se antagoniza com o fenômeno do esquecimento, somos instados a problematizar a lembrança de seu acontecimento-fundador, em 1975, e os desdobramentos de sua vocação nas décadas seguintes.

Ao enfatizar os elementos constitutivos da celebração e da sua relação com a memória e a história do PPGE, destacamos o valor simbólico do ato de rememorar coletivamente, acompanhado de análises sobre as circunstâncias que ele vivenciou ao longo de sua existência.

Nos ajuda Pierre Nora a entender essa relação ao demonstrar que:

[...] a memória emerge de um grupo que ela une, o que quer dizer, como Halbwachs o fez, que há tantas memórias quantos grupos existem; que ela é, por natureza, múltipla e desacelerada, coletiva, plural e individualizada. A história, ao contrário, pertence a todos e a ninguém, o que lhe dá uma vocação para o universal. A memória se enraíza no concreto, no espaço, no gesto, na imagem, no objeto. A história só se liga às continuidades temporais, às evoluções e às relações das coisas. A memória é um absoluto e a história só conhece o relativo (NORA, 1993, p. 9).

A esse propósito, o acontecimento inaugural que ora "rememoramos" busca demonstrar a importância de sua trajetória, impulsionando a continuidade de seu projeto acadêmico para as próximas décadas.

Para facilitar a leitura de nossa escrita, dividimos o artigo em três partes. A primeira discute os primeiros anos de funcionamento do PPGE, passando por uma crise que quase levou ao encerramento precoce de suas atividades no final da década de 1990, até o reconhecimento pelo Ministério da Educação como o primeiro doutorado em Educação do Estado do Paraná, em 2002. Depois, percorreremos os caminhos que confirmaram sua consolidação, com ênfase na importância de sua expansão com os processos de internacionalização, entre aos 
anos de 2002 a 2016. Por fim, a última parte do artigo destaca o enfrentamento de sua projeção com os novos compromissos e desafios que foram sendo postos nos últimos cinco anos (2016-2020).

\section{Parte I: Os anos iniciais: a conquista de uma ideia que se tornou realidade (1975-2002)}

Um dos cenários que ambientaram os preparativos para a criação do Curso de Pós-Graduação em Educação da UFPR, ainda em seu nível de Mestrado, se deu nas antecâmaras do Conselho Universitário e do Conselho de Ensino e Pesquisa da UFPR, espaços institucionais nos quais foi debatido o anteprojeto que resultou na aprovação da Resolução 07/74 (UFPR, 1974), de 22 de agosto de 1974, que autorizou o seu funcionamento. Com o início de suas atividades, em 1975, uma das principais políticas de projeção e fortalecimento estava centrada no seu reconhecimento pelos órgãos federais externos à universidade, e o primeiro deles foi oficializado pelo Conselho Federal de Educação, em 1977, pelo Parecer $n^{\circ}$ 3.173/77 (BRASIL, 1977).

No anteprojeto elaborado pela comissão formada pelas professoras Maria Olga Mattar, Zélia Milléo Pavão e os professores Lauro Esmanhoto e Albano Woiski (CERVI, 1988, p. 174), sua estrutura curricular estava organizada por duas Áreas de Concentração: Metodologia do Ensino e Planejamento Educacional. Entretanto, por sugestão da CAPES/MEC, elas foram, em 1976, substituídas por uma única área: Currículo (GLASER, 1988, p. 52). E naquele contexto, foi primordial a sinergia que o corpo docente construiu para o fortalecimento do Curso de Mestrado, com já foi bem destacado no artigo de Anjos e Bufrem:

Como consequência, integraram-se ao quadro do PPGE professores visitantes, especializados na nova área definida. A área de currículo passa a ser influenciada pelas matrizes conceituais norte-americanas, em razão da formação dos especialistas recém-incorporados, tanto brasileiros que haviam feito o doutorado nos Estados Unidos, quanto quatro doutores norte-americanos. O corpo docente, em 1977, era composto por 25 professores, sendo 5 estrangeiros (ANJOS; BUFREM, 2003, p. 381).

Como podemos perceber no Quadro 1, os estudos sobre o Currículo se tornaram peculiares na história dos anos iniciais do PPGE, primeiro, por 
representar sua produção mais longeva e, segundo, por ter sido em quase três décadas, sozinho ou acompanhado, aquele que testemunhou a vinda de novas áreas, assim como a extinção ou reformulação de outras.

QUADRO 1 - ÁREAS DE CONCENTRAÇÃO E LINHAS DE PESQUISA DO PPGE (1975-2002)

\begin{tabular}{|c|l|}
\hline Período & \multicolumn{1}{c|}{ Área de Concentração } \\
\hline $\mathbf{1 9 7 5 - 1 9 7 7}$ & $\begin{array}{l}\text { Metodologia do Ensino } \\
\text { Planejamento Educacional }\end{array}$ \\
\hline $\mathbf{1 9 7 7 - 1 9 8 3}$ & Currículo \\
\hline $\mathbf{1 9 8 4 - 1 9 9 1}$ & $\begin{array}{l}\text { Currículo } \\
\text { Recursos Humanos e Educação Permanente }\end{array}$ \\
\hline \multicolumn{1}{|c|}{ Linhas de Pesquisa } \\
\hline $1992-1997$ & $\begin{array}{l}\text { Arte-Educação } \\
\text { Cognição, Aprendizagem e Interação Social } \\
\text { Currículo e Conhecimento } \\
\text { Educação e Trabalho }\end{array}$ \\
\hline $\mathbf{1 9 9 8 - 2 0 0 2}$ & $\begin{array}{l}\text { Cognição e Aprendizagem Escolar } \\
\text { Currículo, Conhecimento e Saberes nas Práticas Escolares } \\
\text { História e Historiografia da Educação } \\
\text { Organização e Gestão dos Processos de Formação Humana }\end{array}$ \\
\hline
\end{tabular}

FONTE: Quadro elaborado pela(o)s autora(e)s a partir dos Relatórios Anuais do Curso de Pós-Graduação em Nível de Mestrado da UFPR.

As primeiras dissertações do Curso de Pós-Graduação em Educação foram defendidas em 1977, com os seguintes títulos: As interferências do Micro-Ensino associado à técnica de Flanders no comportamento interativo do professor-aluno (Lauro da Silva Becker) e Avaliação da aprendizagem escolar (Lilian Anna Wachowicz). Seus respectivos autores, ambos docentes do Setor de Educação, posteriormente foram absorvida(o)s como professora(e)s no mesmo Curso de Pós-Graduação em que defenderam suas pesquisas de mestrado. Aliás, esse é um aspecto dessa primeira fase, qual seja, a presença de pós-graduandos que já atuavam como professora(e)s nos múltiplos departamentos da UFPR, os quais procuravam o Curso de Pós-Graduação em Educação para qualificação de sua atuação no ensino superior, além da busca de capacitação para a pesquisa no campo da Educação.

A década seguinte, segundo Niroá Glaser (1988), foi aquela em que foram celebrados os 50 anos de existência do curso de Pedagogia da UFPR (1938-1988) que, desde o seu início, marcou uma série de debates que levantaram 
a necessidade de reformulações na estrutura do Setor de Educação, tais como a instalação do curso noturno de Pedagogia, em 1981; as primeiras eleições diretas para os cargos de Diretor e vice do Setor de Educação, em 1986; a transferência do departamento de Biblioteconomia para o Setor de Ciências Humanas e Letras, em 1987 e, em especial, para a Pós-Graduação, a sua primeira grande reformulação curricular aprovada pela Resolução no 09/83 (UFPR, 1983) do Conselho Universitário, que alavancou, em 1984, a aprovação por sua continuidade, conforme decisão do Conselho de Ensino e Pesquisa referendada no Parecer $n^{\circ}$ 640/84 (UFPR, 1984).

Mas todo o esforço alcançado em seus primeiros quinze anos foi fortemente ameaçado por equivocadas políticas nacionais relacionadas ao serviço público que ameaçaram, seriamente, a continuidade do PPGE. Mesmo assim, a década de 1980 instigou aquela geração de professora(e)s a dar um passo a mais para o aprimoramento e a expansão do PPGE no cenário da pós-graduação paranaense, com a instalação de um grupo de estudos constituído para pensar uma proposta de doutorado, de acordo com a Portaria 07/ED (UFPR, 1982), de 11 de outubro de 1982, e atender às expectativas na formação de pesquisadores doutores em Educação em face de uma realidade que cada dia mais demandava da universidade pública a oferta de cursos de formação, capacitação e qualificação de profissionais aptos a entender os fenômenos educacionais e propor soluções aos seus problemas.

A memória desse debate foi registrada por Rejane Cervi, a mesma que presidiu o referido grupo de estudos, composto pela(o)s professora(e)s Lilian Wachowicz, Heloísa Lück, Wanda Paranhos e Luiz Busato. O resultado desse trabalho foi apresentado em 28 fundamentos que justificavam a defesa de sua implantação, dentre os quais destacamos:

7. Conceituado o Doutorado além de sua definição estrutural, indicase, aqui, um contorno desejável para o Programa Doutoral do Setor de Educação desta Universidade Federal do Paraná que leve em consideração uma função básica de revisão prática educativa brasileira pela pesquisa e pela reflexão, o que, neste caso, o caracterizaria pela PESQUISA NO CAMPO DA EDUCAÇÃO (CERVI, 1984, p. 102).

Antes de sua instalação, não passaram desapercebidas preocupações que deveriam atender os critérios para o seu reconhecimento em diferentes instâncias, tais como: (1) sua projeção no contexto da pós-graduação em educação; (2) quais 
deveriam ser os seus principais enfoques de pesquisa; (3) como se organizaria sua estrutura curricular; e (4) qual o perfil da clientela que atenderia.

A última parte desse documento foi construída a partir da seguinte pergunta: Doutorado quando? Nela estão tabuladas as principais estratégias de ação para a reorganização do Mestrado, as quais viabilizassem uma estrutura de curso de doutorado que garantisse sua implementação e continuidade. De modo bastante pertinente, o relatório da(o)s professora(e)s apresenta um conjunto de considerações que continuam, após quase quatro décadas, necessárias. Senão, observemos a configuração de suas ponderações:

A. Produção e absorção da pesquisa:

A.1 Mobilização departamental no sentido de garantir espaço para a pesquisa e sua intensificação;

A.2 Facilitação da veiculação dos resultados, parciais ou globais, das pesquisas, seja por favorecimento de sua publicação, seja pela realização sistemática de "fórum"(s).

B. Organização da Estrutura Curricular:

B.1 Criação e organização de Seminários Interdisciplinares dentro e fora das linhas de pesquisa vinculadas ao Mestrado. Tais seminários comporão, ao lado dos cursos monográficos, a estrutura da oferta curricular do curso de Doutorado;

B.2 Criação e organização de cursos monográficos de interesse para

o Programa. Convocação dos Doutores e discussão da concepção pedagógica de cursos monográficos e seminários;

B.3 Integração do Setor de Educação com outros Setores para diversificação da oferta de cursos monográficos.

C. Desenvolvimento de estratégias de cooperação com outras instituições: C.1 Realização de convênios interinstitucionais para pesquisa conjunta a nível regional, nacional e/ou internacional.

D. Assunção coletiva da proposta:

D.1 Realização de um ciclo de encontros, a nível interno do Setor de Educação, para consolidação da proposta do Programa de Doutorado, a fim de proporcionar a seus docentes oportunidades coletivas e sistemática de:

a) revisar criticamente a documentação legal vigente;

b) analisar e discutir "concepções" de Doutorado;

c) optar pela adoção de uma proposta científica.

E. Garantia Institucional:

E.1 Realização de convênios com agências de cooperação técnica e assistência financeira, ligadas ou não ao MEC (CERVI, 1984, p. 109-110). 
Esse foi o documento que registrou oficialmente, pela primeira vez, a vocação e o desejo promissor de formação de doutores em Educação na Universidade Federal do Paraná. Contudo, diante de inúmeras adversidades que se prolongaram até o início dos anos de 1990, esse processo teve, infelizmente, retardada sua execução, para ser retomado no início do século XXI. O novo projeto apresentou fundamentos semelhantes àqueles que anteriormente tinham sido pautados pelo grupo de 1982, mas que foram atualizados para a nova realidade da pós-graduação brasileira que, em outro formato, restabelecia a ideia de um curso de doutorado, tornando-se uma importante guinada nos rumos da História do PPGE, assunto que trataremos imediatamente a seguir.

\section{Parte II: Os anos de consolidação: do reconhecimento do primeiro doutorado em Educação do Estado do Paraná à Internacionalização (2002-2016)}

Após o período inicial em que o PPGE começa e amplia sua trajetória como referência para a formação de mestres em educação, ainda nos anos de 1990, são ampliadas as discussões sobre o pedido de autorização para a oferta do doutorado. Esse processo não ocorre de forma isolada em relação aos demais Programas de Pós-Graduação do país, pois existem condicionantes contextuais que impõem mudanças nos Programas. De acordo com Kuenzer e Moraes (2005) e Moraes (2002), é justamente na segunda metade da década de 1990, quando a Capes apresenta um novo paradigma de avaliação, que se consolida a concepção da pós-graduação como lócus privilegiado da pesquisa e da produção de conhecimento. Em 1998, quando pululavam inquietações sobre a necessidade do estabelecimento de novos parâmetros de avaliação para a pós-graduação, a Capes anunciou novas exigências para garantir padrões internacionais de qualidade (SEVERINO, 2009). Nesse novo cenário, houve um forte estímulo/exigência para que os Programas ajustassem suas propostas para ofertar cursos de doutorado.

Em decorrência dessas novas políticas, no período compreendido entre 2002 e 2016, adveio um processo de ampliação gradual dos Programas de Pós-Graduação no Brasil. Em específico, houve um aumento nos programas com oferta de doutorado. Segundo os dados do GEOCAPES, o país tinha 891 programas de pós-graduação acadêmicos com mestrado e doutorado em 2002. Já em 2016, esse número ascendeu para 2.106 programas em funcionamento, o que representou um acréscimo de $136 \%$ no número de programas com mestrado 
e doutorado. No caso do estado do Paraná, em 2002 existiam 35 programas de pós-graduação acadêmicos com mestrado e doutorado considerando-se todas as áreas de pesquisa. Em 2016, esse número havia aumentado para 150, o que representou um aumento de $329 \%$ no número de programas de pós-graduação. Assim, é possível dizer que o Paraná superou a média nacional e acompanhou uma tendência de aumento, que foi balizada pelas políticas indutoras e de regulamentação da Capes, iniciada nos anos de 1990.

Nesse contexto, vale sublinhar que esse processo de ampliação do número de programas ocorreu de forma assimétrica ao longo do território nacional. Os estudos de Cirani, Campanario e Silva (2015) e de Guimarães, Brito e Santos (2020) demonstram que não houve um processo de desenvolvimento e expansão homogêneo dos programas em todas as regiões do país. De acordo com Cirani, Campanario e Silva (2015), as regiões com maior desenvolvimento econômico tiveram uma ampliação mais rápida e intensa, assim como obtiveram maiores investimentos financeiros, tanto em relação ao número de bolsas de estudos como em relação aos auxílios para a realização de pesquisas. No caso do Paraná, essa realidade se reafirma em termos regionais, tendo em vista que é na capital do estado que há um maior desenvolvimento das atividades econômicas, onde surge o maior número de programas de pós-graduação e o primeiro programa de pós-graduação em Educação. Isto ocorreu no ano de 2001 na Universidade Federal do Paraná.

Ao analisar a trajetória do PPGE da UFPR, Anjos e Bufrem (2003) destacam que na década 1990, após a superação de algumas dificuldades e com a incorporação de novos professores ao Programa, foi possível aprofundar, por meio de um processo de autoavaliação, o debate sobre a concepção curricular e a vocação do PPGE. Desse movimento resultou uma nova proposta curricular em 1998 e se intensificaram os debates sobre a criação do doutorado. Nesse processo de reestruturação, foi realizado o diagnóstico e o mapeamento da produção docente e discente do curso com a finalidade de identificar suas características e definir a manutenção, ou não, das linhas de pesquisa existentes, bem como foram avaliadas as condições para criar novas linhas.

De acordo com os dados dos relatórios anuais do Programa, no final dos anos de 1990 houve um esforço institucional para cumprir as condições necessárias para a criação do curso de Doutorado e para fazer um deslocamento da centralidade na docência para a pesquisa, conforme indicavam os documentos da Capes naquele período. Esse processo também demandou uma avaliação de toda a trajetória do PPGE e uma reavaliação do potencial a ser mobilizado para o desenvolvimento das atividades formativas do doutorado. Segundo Silva (2016), "a criação do Doutorado implicou a definição de uma nova organização curricular". Essa reformulação alterou a estrutura formativa que já existia e redefiniu a área de concentração e as linhas de pesquisa. 
A proposta de criação do Doutorado apresentada no ano de 2000 se constituiu em um marco na história do PPGE, já que, por um lado, denotava a maturidade da trajetória do Programa, e por outro, se constituía em uma ocasião favorável para uma revisão das práticas formativas e para a consolidação da produção do corpo docente. Segundo Anjos e Bufrem (2003), a proposta ainda não refletia a realidade da pesquisa no Setor de Educação, em razão das limitações identificadas e do reajuste decorrente da participação de novos doutores. No entanto, é inegável sua contribuição para a consolidação de novas possibilidades de formação. A nova proposta definiu que a estrutura do Programa seria composta por:

Área de Concentração, três áreas temáticas, e, ligadas a essas áreas temáticas, as linhas de pesquisa. Foi definida como área de concentração "Educação, Cultura e Tecnologia" e como áreas temáticas: História e Historiografia da Educação; Educação e Trabalho; Cultura e Processos de Ensino-Aprendizagem. Ligadas às áreas temáticas estavam as linhas de pesquisa: História e Historiografia da Educação; Políticas e Gestão da Educação, Mudanças no Mundo do Trabalho e Educação; Educação, Ambiente e Sociedade; Cognição, Aprendizagem e Desenvolvimento Humano; Cultura, Escola, Ensino; e Educação Matemática (SILVA, 2016, p. 238).

Ainda no ano de 2000, a proposta de doutorado foi aprovada pela Capes e, a partir de 2001 o curso começou a ser ofertado. Os primeiros dados em relação as suas atividades foram registrados para fins de avaliação a partir de janeiro de 2001. O primeiro processo seletivo para o doutorado disponibilizou vagas nas seguintes áreas temáticas: Economia política da educação (8 vagas); Educação e profissionalização: políticas e processos (2 vagas); Educação matemática e processos de aprendizagem (2 vagas) e Saberes, cultura e práticas escolares (2 vagas). Do grupo de professores que atuavam no PPGE nesse período, apenas uma das professoras continua ofertando vagas de doutorado até o ano de 2020.

A primeira defesa de tese ocorreu no final do ano de 2003 e representou a materialização de um esforço coletivo. A implementação do doutorado em Educação na Universidade Federal do Paraná foi importante não só do ponto de vista institucional, mas também representou uma conquista para a sociedade curitibana e paranaense, porquanto se constituiu em uma possibilidade de formação de novos quadros para todas as instituições do estado, tanto para o Ensino Superior, como para a Educação Básica. 
Mais adiante, já no ano de 2007, sob o balizamento dos critérios de avaliação estabelecidos pela Capes e com o amadurecimento dos processos de formação a partir da oferta do doutorado, foi preciso repensar o conjunto das ações e condições estruturais do Programa. Essa tessitura exigiu os esforços de professores, técnicos e discentes para a realização de um processo de autoavaliação de cada linha de pesquisa. Em especial, foi preciso analisar o perfil da produção científica dos docentes, os resultados, os impactos das pesquisas e o potencial de oferta de novas vagas em cada uma das linhas. Desses esforços resultou uma nova proposta de ajuste curricular, com reformulações das Linhas de Pesquisa (encerramento e criação de linhas) e a oferta de novas disciplinas.

Em 2008, além de ter sido concluída a proposta de ajuste curricular, o Programa obteve o conceito 5 na avaliação da Capes e foram aprovadas suas normas internas, consolidando uma nova perspectiva de atuação para afiançar suas condições de funcionamento e continuidade. Nesse contexto, houve uma melhor definição dos créditos necessários à formação tanto no mestrado como no doutorado, bem como se operou um realinhamento entre os projetos de pesquisa e as disciplinas do Programa. Essa reformulação foi levada a efeito a partir das turmas ingressantes no processo seletivo de 2010. Nesse período se reafirmou a centralidade da pesquisa e da formação para e por meio da pesquisa como eixo estruturante da práxis coletiva do Programa. Porque, conforme repisa Saviani (2000), o objetivo precípuo da pós-graduação stricto sensu é a formação do pesquisador, e esse é o elemento central em torno do qual ela deve ser organizada, considerando seus dois níveis, mestrado e doutorado.

Assim, de acordo com Silva (2016), nos anos de 2011 e 2012 houve um período de transição, pois as novas turmas começaram os cursos de mestrado e doutorado com um novo regime de créditos (18 para o mestrado e 36 para o doutorado). De acordo com os relatórios anuais desse período, também se identifica que houve um movimento mais amplo de reestruturação do Programa, o que na prática, poderia representar a necessidade de divisão do PPGE em dois ou três novos programas. Após inúmeras avaliações, essa ideia não foi levada a efeito, no entanto, foi realizada uma reorganização das linhas de pesquisa.

No ano de 2012, sob a convergência para a área de concentração definida como "Educação", o Programa contava com cinco linhas de pesquisa, nomeadamente: História e Historiografia da Educação; Políticas Educacionais; Trabalho, Tecnologia e Educação; Cultura, Escola e Ensino; Cognição, Aprendizagem e Desenvolvimento Humano. Essa configuração se manteve nos anos seguintes, até a criação das linhas de Diversidade, Diferença e Desigualdade Social em Educação (2016); Processos Psicológicos em Contextos Educacionais (2018); Linguagem, Corpo e Estética (2019) e a extinção da linha Trabalho, Tecnologia e Educação em 2014. 
Visando superar as assimetrias regionais no país, a partir de 2008 a Capes divulgou chamadas públicas para o recebimento de propostas de implantação de redes de cooperação acadêmica. O edital no 013/2011 (CAPES, 2011) teve o objetivo de instruir a apresentação de propostas de Mestrado Interinstitucional (MINTER) e de Doutorado Interinstitucional (DINTER), visando a formação de recursos humanos qualificados para o desenvolvimento socioeconômicocultural, científico-tecnológico e de inovação para o país. Esse processo indutor visou ampliar a formação de mestres e doutores para o quadro permanente de instituições distantes dos grandes centros de ensino e pesquisa, de modo a diminuir as assimetrias regionais existentes. Nesse contexto, como parte importante do processo de consolidação do PPGE, foram realizadas ações para levar a efeito uma proposta de cooperação por meio da oferta de um DINTER. Esse processo foi iniciado no ano de 2011 e exigiu forte mobilização do Programa, tendo em vista as demandas que essa iniciativa representaria. A partir de 2012, numa ação conjunta com a Universidade Federal do Acre, foi iniciada a primeira turma do DINTER (2012/2016), com um grupo de 25 doutorandos. Em 2017, a proposta foi retomada com alguns ajustes em relação à primeira experiência. Assim, a segunda edição começou no ano de 2018 (2018/2022) com uma turma de 14 doutorandos.

Por meio do programa de apoio à capacitação de docentes das instituições estaduais de ensino superior - PCD-IEES (Chamada/ano: 10/2010), outro processo de cooperação e solidariedade foi realizado com início no ano de 2011. Desta vez, em parceria com a Universidade Estadual do Paraná (UNESPAR), mais especificamente com a Faculdade Estadual de Filosofia, Ciências e Letras de União da Vitória (FAFIUV) e a Faculdade Estadual de Filosofia, Ciências e Letras de Paranaguá (FAFIPAR), atualmente, Campus de Paranaguá, foi realizada a formação de quatro doutores para atuar nas respectivas instituições. A partir dessa iniciativa, foram efetivadas as seguintes ações: formação de quatro docentes da UNESPAR em nível de doutorado; publicação de artigos científicos; apresentação dos resultados das pesquisas em congressos internacionais e uma visita técnica à Universidade do Texas em Austin. Essas ações fortaleceram e ampliaram as relações do Programa com outras instituições, revelando uma ontológica vocação para ações de solidariedade, nucleação e de internacionalização.

O resultado da avaliação do quadriênio 2013/2016, divulgado no ano de 2017, indicou uma elevação da nota do Programa, ou seja, a nota passou de 5 para 6. Assim, o PPGE passou a ser considerado como um Programa de Excelência Internacional. Esse resultado consolidou uma longa trajetória de trabalho e de muitos esforços coletivos para qualificar os processos de Ensino e Pesquisa, bem como deu destaque aos resultados obtidos nas pesquisas desenvolvidas por 
docentes, mestrandos e doutorandos ao longo de diversos anos. No entanto, ao mesmo tempo, tal conquista também implicaria uma série de novos desafios a serem enfrentados a partir de então.

No bojo desse novo contexto, tomaram relevo as ações de internacionalização que já estavam em desenvolvimento no Programa. De acordo com Carvalho e Real (2020), para que os programas de pós-graduação alcancem determinado nível de excelência esperado para os programas de notas 6 e 7, há outros indicadores que são apensados aos critérios de avaliação, dentre eles, destacável é a internacionalização, posto como um dos desafios centrais, por sua relevância para a circulação do conhecimento, para a formação de recursos humanos e para a integração de diferentes ações e investimentos de pesquisa.

Por força do cenário que se impunha pela nota obtida pelo Programa, foi preciso identificar e valorizar todas as iniciativas de cooperação internacional, sendo elas caracterizadas por projetos de pesquisa realizados em rede, formações em modalidade pós-doutorado ou doutorado-sanduíche, realização de missões de trabalho em outros países, recepção de professores visitantes, ampliação das ações de cooperação científica com instituições estrangeiras, publicações internacionais etc., mas sobretudo, foi preciso envidar esforços na busca de condições para que essas ações fossem levadas a efeitos e que seus resultados tivessem impacto científico e social. Neste sentido, a aprovação do Programa de Internacionalização da UFPR pela Capes (Capes-Print/2018) foi um marco importante para o PPGE, pois criou melhores condições para favorecer os processos de internacionalização.

Por outro lado, ainda como indicativo do amadurecimento e consolidação do PPGE, as ações relacionadas às políticas afirmativas ampliaram e qualificaram o nível de democratização do Programa. Por meio de iniciativas como a do Projeto Formação Pré-Acadêmica Afirmação na Pós UFPR (Pré-Pós), iniciado em 2013, sob a coordenação do Núcleo de Estudos Afro-brasileiros (NEAB-UFPR), núcleo de pesquisa vinculado ao PPGE, foi realizado um processo exitoso no âmbito do Programa Equidade na Pós-Graduação, o que resultou na ampliação das possibilidades de acesso à pós-graduação para determinados grupos de pessoas. A abertura de vagas para negros, indígenas, quilombolas, pessoas trans - transexuais, transgêneros e travestis -, pessoas com deficiência, surdos/ as, migrantes humanitários e refugiados foi um avanço significativo na práxis do Programa. Valeria sublinhar aqui que esse processo decorre da ampliação das pesquisas no âmbito da diversidade, da diferença e da desigualdade social, já que, sem uma ampla compreensão do tema, não seria possível intervir para minimizar essas assimetrias e injustiças sociais. 


\section{Parte III: Os anos de projeção: da internacionalização a outros desafios contemporâneos (2016-2020)}

Um dos maiores desafios para o PPGE após a avaliação quadrienal da Capes, que abrangeu o período de 2013 a 2016, constituiu-se na busca de sua consolidação como Programa de Excelência Internacional. A dedicação em relação a esse aspecto pode ser constatada a partir da leitura dos relatórios anuais, depositados nos arquivos digitais da secretaria de sua Coordenação, enviados para a agência de fomento, com a finalidade de compor o quadro de avaliação e desempenho. Verifica-se a tentativa de reunir as amplas e diversificadas atividades realizadas pelos professores do Programa junto a diferentes países. Evidentemente, não cabe enumerar neste documento todas as atividades realizadas pelos professores ao longo desses quatro anos, num exercício de mera reprodução das informações dos relatórios. No entanto, cabe indicar a realização de atividades que vão desde a participação em grupos de pesquisa a conferências em eventos internacionais, do estabelecimento de convênios a publicações conjuntas de livros e dossiês de línguas estrangeiras, da participação em estágios como professores visitantes à realização de pós-doutorados e cursos de curta e longa duração. A partir dessas ações, a UFPR, com forte participação do PPGE, alçou voos para o estabelecimento de importantes parcerias com instituições de Ensino Superior de países da América Latina, como Argentina, Chile e México; da Europa, como Alemanha, França e Portugal; e de outros países como Marrocos, Índia, Estados Unidos, Israel e Austrália, para citar apenas alguns.

A partir da leitura dos relatórios, foi possível observar que o caminho da internacionalização já se estabelecia como algo progressivo, em pleno desenvolvimento, e que a mudança de patamar, resultado da última avaliação quadrienal, seria apenas uma consequência lógica, caso não houvesse disparidades significativas ou interferências adversas provocadas por mudanças bruscas nos itens e parâmetros de avaliação. Todavia, determinante para a continuidade do fortalecimento desses laços internacionais de pesquisa, foi a criação, entre 2017 e 2018, do Programa Institucional de Internacionalização, o Capes-Print. Esse Programa estabeleceu, por meio de editais específicos, recursos para o financiamento de missões de trabalho no exterior, manutenção de projetos e bolsas no exterior e no país (doutorado, pós-doutorado e professor visitante). A UFPR, a partir de uma articulação feita pela Pró-Reitoria de Pesquisa e Pós-Graduação, obteve êxito no seu primeiro pleito ao edital de seleção de projetos para o Capes-Print. A proposta contou com a participação de professores permanentes do PPGE para a elaboração de alguns dos seus projetos 
iniciais: Produção e Circulação de Saberes; Políticas Públicas e Mudanças Sociais; Relações de Poder; Assimetrias e Direitos Humanos; SmartMinds: Internacionalização das Humanidades na Esfera Pública Digital; e Espaço, Sociedade e Desenvolvimento.

A oportunidade de internacionalização, entendida em uma perspectiva de intercâmbio e estágios sanduíches de doutorado, também se estendeu como oportunidade aos estudantes mediante a participação em editais específicos de concorrência. No entanto, a dependência de bolsas de estudo é uma condição para a maioria dentre aqueles que se candidatam ou demonstram interesse de realizar parte de sua pesquisa no exterior. Para além de questões financeiras, decorrentes de diferentes realidades sociais e não incomuns à realidade acadêmica brasileira, há o grande desafio de formação dos estudantes para habilitação linguística, considerando as exigências feitas principalmente para os exames do TOEFL (Test of English as a Foreign Language), tendo em vista as características da formação secundária e de nível superior, que nem sempre privilegiam de forma satisfatória a língua estrangeira em sua grade curricular. Feita essa constatação, a Universidade e as coordenações do PPGE têm se preocupado em disponibilizar ferramentas para a capacitação de seus pós-graduandos, sugerindo ações de oferta de cursos e oficinas direcionadas, possibilitadas a partir de parcerias dentro e fora da UFPR. As capacitações também visam desenvolver o hábito ampliado de leitura em outros idiomas, agregando às pesquisas desenvolvidas na instituição a possibilidade de conhecimento e compreensão de conteúdos não publicados em língua portuguesa.

A internacionalização caracteriza-se como um indicador de crescimento qualitativo do PPGE, mas também indica um crescimento quantitativo no que diz respeito ao seu corpo docente e discente. Fazer funcionar bem a engrenagem de base foi fundamental para que o PPGE pudesse almejar voos mais altos. Neste último quadriênio, o corpo docente do Programa tem se ampliado pelos ingressos anuais organizados por editais elaborados pela Comissão Permanente de Avaliação (CPA), que elevaram a quase uma centena a quantidade de professores ativos no PPGE, entre permanentes e colaboradores. Como consequência disso, a quantidade de orientandos de mestrado e doutorado se ampliou, chegando ao final do quadriênio 2017-2020 com mais de 500 discentes. A operacionalização administrativa, por sua vez, se tornou maior e mais complexa, exigindo não apenas uma Coordenação comprometida, mas também um corpo técnico engajado, visando ao bom desenvolvimento das rotinas comuns ao Programa, tais como: organização do processo seletivo, realização de matrículas, ensalamentos, agendamento de bancas, controle financeiro, dentre outras múltiplas demandas de atendimento direto e indireto a docentes, estudantes e comunidade interna e externa da instituição. 
O histórico de parte da rotina administrativa do PPGE pode ser constatado pela leitura das atas de reunião de seu Colegiado, constituído por membros da coordenação, representantes das linhas de pesquisa e representantes discentes. As atas estão disponíveis no acervo digital do Programa, e por meio delas é possível ter uma noção da dimensão de demandas referentes à rotina administrativa, desde a aprovação de qualificações e bancas de defesa, ad referendum ou não, à aprovação de exames de suficiência e solicitações de aproveitamento de créditos. Há pautas de discussão de temas mais sensíveis ou excepcionais, em que se pode destacar a natureza democrática dos encaminhamentos, refletindo o respeito e o cuidado dado para diferentes posicionamentos e opiniões, característica comum de um corpo docente significativamente amplo e de linhas de pesquisa com naturezas distintas. Ao longo de 2018, o PPGE reformulou as suas normas internas, vindo a publicar sua versão mais recente em março do ano seguinte. Colocou em pauta a reformulação de sua grade curricular, atualizando nomes de disciplinas, ementas e bibliografias, conforme as novas características definidas para o Programa.

Cabe destacar que o PPGE também passou por uma mudança em relação aos espaços físicos. Desde a sua criação o programa funcionava no Campus da Reitoria, no edifício D. Pedro I; em junho de 2018, mudou-se junto com parte do Setor de Educação para o Campus Rebouças, há aproximadamente $1,5 \mathrm{~km}$ de distância, onde passou a funcionar no edifício Teixeira Soares, em instalações cedidas à UFPR pela antiga Rede Ferroviária Federal Sociedade Anônima (RFFSA). A mudança condicionou a criação de novos espaços para a secretaria, para salas de aula, laboratórios e parte dos gabinetes de professores. Como toda mudança física, foi necessário contar com a colaboração de professores, técnicos e alunos para a adaptação ao novo espaço, que, aos poucos, foi recebendo melhorias de acordo com as necessidades impostas às rotinas de aulas, orientações, pesquisa e serviços administrativos. Se, por um lado, houve transtornos naturais decorrentes dessa mudança; por outro, houve ganhos significativos, como a cedência de espaços maiores e mais apropriados que atendessem as demandas de um Programa em plena projeção. As mudanças em relação ao local e ao uso dos espaços físicos repercutiram em mudanças virtuais, como a reformulação do site do PPGE - em parte padronizado pela Pró-Reitoria de Pesquisa - e a criação de outros espaços de comunicação e publicidade, como redes sociais, para a divulgação de atividades, e plataformas de vídeo, para a divulgação de conteúdo.

Se, por um lado, aspectos da consolidação e projeção do PPGE perpassam as ações e iniciativas do próprio Programa - individuais e coletivas -, por outro, há de se considerar a instabilidade política pela qual o Brasil vem passando neste último quadriênio. $\mathrm{Na}$ esfera federal, passamos por um processo de 
impeachment presidencial em agosto de 2016, já antecedido por um processo eleitoral muito turbulento no ano anterior. $\mathrm{O}$ governo que assumiu, entre agosto de 2016 e dezembro de 2018, trouxe muitas incertezas e novos desafios às políticas educacionais no país, entre outros temas, mas repercutiu também nas políticas de organização e financiamento da educação superior, incluindo a pós-graduação. Sobre o atual governo presidencial, que assumiu em janeiro de 2019, deixamos as críticas a cargo das repercussões nacionais e internacionais, mas de nosso interesse cabe destacar as modificações feitas na Capes e, em especial, na sua área de avaliação. Conforme mencionando anteriormente, a leitura dos relatórios emitidos pelo PPGE para a agência de fomento indica sua natural projeção à internacionalização e, consequentemente, à consolidação nesse patamar - salvo mudanças adversas. A redução de bolsas de pós-graduação, para além do exemplo da redução substancial de áreas do conhecimento, pode ser entendida como reflexo de uma política indiferente aos problemas da pós-graduação brasileira, especialmente da pós-graduação em Educação, refletindo diretamente no cotidiano e na produção de pesquisa dos estudantes. Apesar disso, o PPGE segue, de forma coletiva, acreditando na democracia como elemento norteador de suas ações. Em 2019, o Programa realizou pela primeira vez um processo seletivo com ações afirmativas que contemplou a população negra, quilombolas, indígenas, pessoas trans, pessoas com deficiência, surdos/as e migrantes humanitários e refugiados. Esse fato agregou valores e consolidou ainda mais os valores em que a história do programa tem se pautado, indicando clareza em suas perspectivas políticas e demarcando seus territórios de compreensão da sociedade.

Em uma história que continua sendo escrita, um grande desafio ainda estava por vir. Em março de 2020, o PPGE fechou as portas presenciais da Universidade em decorrência da pandemia de COVID-19, que chegou ao Brasil e demandou rápidas adaptações. Assim como nas demais instituições, somaram-se possibilidades virtuais, como a realização de atendimentos remotos e, posteriormente, a operacionalização de bancas de defesa remotas. A adaptação e a familiarização a esta nova realidade expandiram-se para a retomada dos semestres de forma remota, com aulas ministradas em plataformas de conferência eletrônica e uso de outras ferramentas oferecidas pelas tecnologias contemporâneas, sem perder a percepção de realidade quanto ao acesso à cultura digital por parte da comunidade acadêmica. O PPGE estabeleceu ainda a realização remota do processo seletivo de novos estudantes de mestrado e doutorado, em formato específico, e, apesar das adversidades, obteve mais de mil candidatos inscritos, demandando, por sua vez, uma organização operacional ainda maior para a efetividade e sucesso da seleção. 
Em um período de grandes adversidades, cabe destacar a capacidade do PPGE de se projetar e buscar sua consolidação de acordo com suas características e com as métricas definidas pelas agências de fomento, incluindo também sua capacidade de se reinventar, de enfrentar as dificuldades, de prezar pela democracia e de não perder o sentimento humanitário e de solidariedade. Itens que se estivessem nos critérios de avaliação, certamente seriam muito bem pontuados.

\section{Considerações finais}

A oscilação entre a presença e a ausência que nos remete à comemoração de uma data ou de um ciclo específico, como indicado por Mona Ozouf (1999, p. 31), tangencia a percepção de um PPGE presente, contemporâneo, em atividade contínua, que não apenas simboliza, mas se faz presente enquanto espaço físico-institucional e enquanto ambiente efetivo de ações da sua comunidade acadêmica. Os vestígios que atravessaram os anos, como documentos administrativos acondicionados em seu arquivo, agregam delineamentos à narrativa reelaborada daqueles que vivenciaram seus diferentes momentos. As origens do PPGE estão documentadas nas atas do Conselho Universitário e do Conselho de Ensino e Pesquisa da UFPR, que indicam sua aprovação em resolução específica publicada com a data de 22 de agosto de 1974 (UFPR, 1974), tendo seu efetivo funcionamento ocorrido a partir do ano seguinte. Em termos do tempo cronológico, nos aproximamos de meio século de existência, do fechamento de um ciclo, que incita às comemorações, e à consequente celebração da ausência e da presença.

Para além dos registros da autorização do seu funcionamento e das discussões para a criação do curso de Doutorado na década de 1990, que veio a se efetivar nos anos 2000, temos a reflexão sobre o impacto que o PPGE teve na sociedade com a formação de mestres e doutores ao longo de todos esses anos. São imensuráveis as transformações individuais nas carreiras profissionais, obviamente, mas também nas suas formas mais amplas, materializadas nas qualificações das representações docentes replicadas nas redes pública e privada de ensino, nos cargos administrativos da Educação em suas diferentes instâncias, dentre outras possibilidades de o conhecimento produzido no PPGE, engendrado pelo produto de aulas da pós-graduação e em pesquisas que resultaram em dissertações de mestrado e teses de doutorado, alcançar espaços para além dos muros da universidade, atingindo aqueles que, no seu dia a dia, dela se encontram muito distantes. 
O amadurecimento do PPGE também ressignificou e aumentou as suas responsabilidades, desde a ampliação e diversificação de suas linhas de pesquisa até a ampliação do seu quadro docente, o envolvimento em atividades de cooperação como o DINTER, desde 2012, a busca e a consolidação do conceito 6 junto à Capes e o investimento no Programa de Internacionalização da UFPR, desde 2018. E para além dos desafios administrativos, também há os desafios humanos, de gerência das relações pessoais e de sensibilização quanto a possíveis interferências decorrentes de variados problemas sociais. E muitas vezes, vale sempre lembrar, seguindo um caminho cuja trilha ainda não indicava claramente para qual direção seguir. Nesse sentido, gostaríamos de agradecer aos professores que se dispuseram a assumir esse desafio estando à frente da Coordenação do Programa nos seus diferentes momentos ao longo dessa história ainda em construção, cujos nomes contemplamos no quadro a seguir.

\section{QUADRO 2 - COORDENADORES E VICE-COORDENADORES DO PPGE}

\begin{tabular}{|c|c|}
\hline Período & Coordenador(a) \\
\hline 1974-1977 & Lauro Esmanhoto \\
\hline 1978-1981 & Verner Artur Conrado Barthelmess \\
\hline 1979-1980 & Verner Artur Conrado Barthelmess e Elpidio Marculino Cardoso \\
\hline 1981 & Verner Artur Conrado Barthelmess \\
\hline $1982-1983$ & Verner Artur Conrado Barthelmess e Onilza Borges Martins \\
\hline 1984-1985 & Onilza Borges Martins e Maria do Rosário Knechtel \\
\hline 1986 & Onilza Borges Martins e Heloísa Lück \\
\hline 1987 & Heloísa Lück \\
\hline 1988-1991 & Rejane de Medeiros Cervi e José Alberto Pedra \\
\hline 1991-1993 & José Alberto Pedra \\
\hline 1994-1996 & José Alberto Pedra e Maria Cecília de Oliveira \\
\hline 1997-1998 & Maria Tereza Carneiro Soares e Maria Lucia Faria Moro \\
\hline $1999-2000$ & Maria Auxiliadora Moreira dos Santos e Marta Pinheiro \\
\hline $2001-2002$ & Carlos Eduardo Vieira e Marcus Levy Bencostta \\
\hline $2003-2004$ & Lígia Klein e Regina Maria Michelotto \\
\hline $2005-2006$ & Marcus Aurélio Taborda de Oliveira e Claudia Barcelos de Moura Abreu \\
\hline $2006-2007$ & Tânia Maria Baibich e Maria Tereza Carneiro Soares \\
\hline $2007-2008$ & Maria Tereza Carneiro Soares \\
\hline $2008-2010$ & Ângelo Ricardo de Souza e Noela Invernizzi \\
\hline $2011-2012$ & Paulo Vinicius Baptista da Silva e Mônica Ribeiro da Silva \\
\hline $2013-2014$ & Mônica Ribeiro da Silva e Maria de Fátima Quintal \\
\hline $2015-2016$ & Mônica Ribeiro da Silva e Maria Rita César \\
\hline $2016-2017$ & Maria Rita César \\
\hline $2017-2019$ & Geraldo Balduíno Horn e Jean Carlos Gonçalves \\
\hline $2019-2020$ & Marília Andrade Torales Campos e Cláudio de Sá Machado Jr. \\
\hline 2020-Atual & Elisângela Alves da Silva Scaff e Andréa Barbosa Gouveia \\
\hline
\end{tabular}

FONTE: Quadro elaborado pela(o)s autora(e)s a partir da documentação do Programa de PósGraduação em Educação da UFPR e do relato de pessoas que nos serviram de fonte. 
Deixamos um agradecimento a todos os professores que estiveram no quadro do PPGE ao longo deste quase meio século de existência, oferecendo disciplinas, orientando pesquisas de mestrado e doutorado e desenvolvendo trabalhos em seus núcleos, laboratórios e grupos de pesquisa. A percepção de crescimento do Programa ocorre, fundamentalmente, pelas ações e pelo esforço coletivo. O nosso agradecimento também se direciona ao quadro de servidores técnicos pela sua importância em garantir a fluidez de nossa rotina administrativa, sendo estes os principais responsáveis pelos atendimentos públicos, pelos despachos burocráticos, pela organização dos processos seletivos e pela redação de atas e demais documentos indispensáveis para o cotidiano da secretaria. Agradecemos a todos e todas que durante os últimos 45 anos foram responsáveis pela organização técnico-administrativa do PPGE, aos quais nomeamos por meio da composição atual da equipe de secretaria, composta por Sandra Maciel de Lima, Patrícia Kussaba, Cinthia Marloch e Wellen Laynes. Um agradecimento último, ainda, aos diversos estagiários que colaboraram com a rotina da administração.

Cientes das limitações deste recorte cronológico e narrativo, retomamos a afirmativa do início deste texto atribuída a Pierre Nora (1993, p. 9), de que a história pertence a todos e a ninguém. Contemplamos, em algumas poucas linhas, fragmentos selecionados de continuidades temporais de ordem cronológica, a partir de documentos e memórias sobre a década de 1970 até a contemporaneidade. Inevitavelmente produziremos um discurso absoluto, para além do relativo, e estaremos consequentemente sujeitos a eventuais supressões, que pelo fato de deixarem de ser mencionadas, não intencionalmente, deixaram de estar lá. A história do PPGE não é exclusiva, e por isso é de todos. Deve continuar a ser construída de forma coletiva, (re) apropriada em diferentes momentos e gerações, e reescrita quantas vezes for necessário. Uma história que não se encerra com a narrativa, que atravessa o tempo. Por fim, inscreve-se e desenvolve-se livremente na memória daqueles que a vivenciaram: múltipla e plural. 


\section{REFERÊNCIAS}

ANJOS, Liane dos; BUFREM, Leilah Santiago. 25 anos do Programa de Pós-Graduação em Educação da UFPR. Educar em Revista, Curitiba, n. 22, p. 377-398, dez. 2003.

BRASIL. Conselho Federal de Educação. Parecer $n^{\circ}$ 3.173, de 12 de maio de 1977. Aprova o funcionamento do Programa de Pós-Graduação em Educação da Universidade Federal do Paraná. Brasília, DF: MEC, 12 maio 1977.

CARVALHO, Eliane Souza de; REAL, Giselle Cristina Martins. Internacionalização e seus reflexos na gestão da qualidade da pós-graduação em Educação. Série-Estudos, Campo Grande, MS, v. 25, n. 54, p. 223-241, maio/ago. 2020.

CERVI, Rejane de Medeiros. O Programa de Pós-Graduação em Educação: uma notícia histórica. Educar em Revista, Curitiba, v. 7, n. 1/2, p. 169-174, jan./dez. 1988.

CERVI, Rejane de Medeiros. Proposta alternativa de Programa de Doutorado em Educação. Fundamento. Educar em Revista, Curitiba v. 3, n. 1, p. 100-110, jan./jul. 1984.

CIRANI, Claudia Brito Silva; CAMPANARIO, Milton de Abreu; SILVA, Heloisa Helena Marques da. A evolução do ensino da pós-graduação senso estrito no Brasil: análise exploratória e proposições para pesquisa. Avaliação (Campinas), Sorocaba, v. 20, n. 1, p. 163-187, mar. 2015. Disponível em: https:/www.scielo.br/scielo.php?pid=S141440772015000100163\&script=sci_abstract\&tlng=pt. Acesso em: 16 out. 2020.

COORDENAÇÃO DE APERFEIÇOAMENTO DE PESSOAL DE NÍVEL SUPERIOR (CAPES). Reformulação do sistema de avaliação da pós-graduação: o modelo a ser implantado na avaliação de 1998. Brasília, DF: Capes, 1998.

COORDENAÇÃO DE APERFEIÇOAMENTO DE PESSOAL DE NÍVEL SUPERIOR (CAPES). Edital $n^{\circ} 013$, de 01 de junho de 2011. Chamada pública de novas propostas de mestrado e doutorado interinstitucionais, Minter/Dinter nacional e internacional. Brasília, DF: Capes, 01 jun. 2011. Disponível em: https://uab.capes.gov.br/bolsas/ premios/46-bolsas-no-pais/7459-minter-e-dinter-capes-setec. Acesso em: 14 out. 2020.

GLASER, Niroá Zuleika Rotta Ribeiro. Educação na história da UFPR: apontamentos para uma minuta cronológica. Educar em Revista, Curitiba, v. 7, n. 1/2, p. 13-58, jan./ dez. 1988.

GUIMARÃES, André Rodrigues; BRITO, Cristiane de Sousa; SANTOS, José Almir Brito dos. Expansão e financiamento da pós-graduação e desigualdade regional no Brasil (2002-2018). Práxis Educacional, v. 16, n. 41, p. 47-71, 2020. Disponível em: https:// doi.org/10.22481/praxisedu.v16i41.7244. Acesso em: 16 out. 2020.

KUENZER, Acacia Zeneida; MORAES, Maria Célia Marcondes de. Temas e tramas na pós-graduação em educação. Educação e Sociedade, Campinas, v. 26, n. 93, p. 1341-1362, dez. 2005. 
MORAES, Maria Célia Marcondes de. Avaliação na pós-graduação brasileira: novos paradigmas, antigas controvérsias. In: BIANCHETTI, Lucídio; MACHADO, Ana Maria Netto (org.). A bússola do escrever. São Paulo: Cortez; Florianópolis: UFSC, 2002. p. 184-214.

NORA, Pierre. Entre memória e história: a problemática dos lugares. Projeto História, São Paulo, n. 10, p. 7-46, 1993.

OZOUF, Mona. Célébrer, savoir et fêter. In: OZOUF, Mona et al. 1789: La commémoration. Paris: Folio Histoire, 1999. p. 9-33.

SAVIANI, Dermeval. A Pós-graduação em educação no Brasil: trajetória, situação atual e perspectivas. Revista Diálogo Educacional, [s. 1.], v. 1, n. 1, p. 1-95, jul. 2000.

SEVERINO, Antônio Joaquim. Pós-graduação e pesquisa: o processo de produção e de sistematização do conhecimento. Revista Diálogo Educacional, [s. 1.], v. 9, n. 26, p. 13-27, jul. 2009. ISSN 1981-416X.

SILVA, Mônica Ribeiro da. O Programa de Pós-graduação em Educação da Universidade Federal do Paraná: 40 anos de inserção na Região Sul do Brasil. In: VIEIRA, Carlos Eduardo; GONÇALVES, Nadia Gaiofatto (org.). Setor de Educação e Curso de Pedagogia na Universidade Federal do Paraná (1938-2014): histórias, memórias e desafios contemporâneos. Curitiba: Editora UFPR, 2016. p. 237-342.

UFPR. Conselho de Ensino e Pesquisa. Resolução $n^{\circ}$ 7, de 22 de agosto de 1974. Autoriza o funcionamento do Curso de Pós-Graduação, em nível de mestrado, no Setor de Educação, com áreas de concentração em "Planejamento Educacional" e "Metodologia do Ensino". Curitiba: UFPR, 22 ago. 1974.

UFPR. Setor de Educação. Portaria $n^{\circ}$ 7, de 11 de outubro de 1982. Cria um grupo de estudos para elaborar a proposta do curso de doutorado do Programa de Pós-Graduação em Educação da Universidade Federal do Paraná. Curitiba: UFPR, 11 out. 1982.

UFPR. Conselho de Ensino e Pesquisa. Resolução $n^{\circ}$ 9, de 24 de outubro de 1983. Aprova a reformulação curricular do Programa de Pós-Graduação em Educação da Universidade Federal do Paraná. Curitiba: UFPR, 24 out. 1983.

UFPR. Conselho de Ensino e Pesquisa. Parecer nº40, de 18 de junho de 1984. Aprova a continuidade do Programa de Pós-Graduação em Educação da Universidade Federal do Paraná. Curitiba: UFPR, 18 jun. 1984.

Texto recebido em 23/03/2021.

Texto aprovado em $05 / 04 / 2021$. 